\title{
Anti-mesothelin CAR Vector-transduced Autologous T-lymphocytes
}

National Cancer Institute

\section{Source}

National Cancer Institute. Anti-mesothelin CAR Vector-transduced Autologous Tlymphocytes. NCI Thesaurus. Code C124650.

Genetically modified, autologous T-lymphocytes transduced with a retroviral vector encoding a chimeric antigen receptor (CAR) consisting of an anti-human tumorassociated antigen (TAA) mesothelin single chain variable frag ment (scFv), the intracellular CD3 zeta T-cell receptor domain and the 4-1BB (cd137) costimulatory domain, with potential immunomodulating and antineoplastic activities. After isolation, transduction, expansion in culture, and reintroduction into the patient, the antimesothelin CAR vector-transduced autologous T-lymphocytes specifically targ et and kill mesothelin-expressing tumor cells. Mesothelin, a cell surface glycoprotein involved in cell adhesion, is overexpressed in a variety of cancer cell types. 